\title{
Application of HCSA expansive agent in crack control of mass concrete
}

\author{
XinGang Wang ${ }^{1,2, \text { a, }}$, ShiGuang Fan ${ }^{1,2 b}$ \\ ${ }^{1}$ CCCC Tianjin Harbor Engineering Research Institute Co., Ltd., Tianjin, China \\ ${ }^{2}$ CCCC First Harbor Engineering Company Ltd., Tianjin, China
}

\begin{abstract}
The open section of the west artificial island of the Hong Kong-Zhuhai-Macao Bridge is a mass concrete structure. The concrete was poured in two times in the vertical direction, that is, the whole bottom plate was poured in the first time, and the middle wall and two side walls were poured in the second time. The side wall and middle wall are easy to crack due to the long time interval between two concrete castings. In order to study the function and effect of HCSA expansion agent in the crack control of mass concrete, the applicable condition of compensating shrinkage in the crack control of mass concrete is analyzed first. Then the effect of HCSA expansion agent was studied in laboratory and field. The experimental results show that HCSA expander has a good expansion effect under laboratory conditions, but it has no expansion effect on the middle side of the mass concrete test block in the engineering site, instead, it will further increase the internal temperature rise of concrete and increase the shrinkage strain of concrete. HCSA expander is helpless for crack control of mass concrete.
\end{abstract}

\section{Introduction}

Due to the large size of the concrete structure and the low thermal conductivity of concrete, the hydration heat of the rubber material is difficult to dissipate quickly, and the internal temperature rise will be very high. In particular, the maximum internal temperature of high-grade mass concrete can reach more than $70^{\circ} \mathrm{C}$, but this temperature will inevitably gradually drop to normal temperature eventually, and the cooling contraction strain caused by this process can reach $400 \sim 500 \times 10^{-6}$, or even more. In addition, after the final setting of concrete, there are dry shrinkage and self-shrinkage, etc. Under the standard state, the final shrinkage of concrete ${ }^{[1]}$ can reach $324 \times 10^{-6}$. The shrinkage of mass concrete at the temperature drop and the final shrinkage of concrete in the standard state can reach $700 \sim 800 \times 10^{-6}$, which is far beyond the ultimate tensile strength of concrete. Therefore, the mass concrete structure is easy to crack due to the constrained effect of these shrinkage deformation ${ }^{[2]}$. Therefore, in order to solve the cracking problem of gross concrete structure, related scholars have made many researches and explorations on the application of expansion agent to compensate gross concrete shrinkage.

The biggest difference between mass concrete and ordinary concrete is that the internal temperature is different. The higher internal temperature of mass concrete may affect the expansion effect of expansion agent. Yan Peiyu et al from Tsinghua University believed that the hydration product with expansion effect generated by sulfoaluminate expansion agent is ettringite (Aft), which will decompose into single-sulfur calcium sulfoaluminate hydrate (AFM) when the hydration environment temperature is higher than $60 \sim 70^{\circ} \mathrm{C}$, thus losing its expansion effect, and ettringite will regenerate when the temperature of concrete drops to room temperature. And eventually lead to concrete cracking ${ }^{[3]}$. You Baokun et al from China Academy of Building Materials Science believed that there was no possibility of delaying ettringite formation in UEA mass concrete ${ }^{[4]}$. According to the research results of Tian Zhichao et al., under the condition that the temperature rise of absolute humidity is simulated by the measured temperature rise curve of the project, the shrinkage compensating concrete prepared with calcium sulfoaluminate -- calcium oxide expansion agent (HCSA) and calcium sulfoaluminate expansion agent (CSA, AEA), only the shrinkage compensating concrete expanded with HCSA. However, the expansion rate of CSA and AEA is almost zero ${ }^{[5]}$. Most of the above researches on mass shrinkage compensating concrete by scholars simulate the internal temperature change of mass concrete by changing the steam curing temperature in the laboratory, which is different from the temperature change of mass concrete caused by glue hydration in actual engineering. In addition, steam cultivation and engineering site maintenance conditions are not exactly the same. Therefore, before the relevant research results or conclusions obtained in the laboratory are applied to the actual engineering, it is still necessary to do experiments under the conditions and environment of the engineering site to further verify its actual effect.

\footnotetext{
"Corresponding author: ${ }^{\mathrm{a}} \mathrm{wxg} 58 @ 126 . \mathrm{com}$
}

bfanshiguang@tpei.com.cn 


\section{Applicable conditions for shrinkage compensation and crack control of mass concrete}

\subsection{Analysis of the role of compensating shrinkage in crack control of mass concrete}

The shrinkage deformation of mass concrete, according to the different constraints, will mainly cause two types of stress: one is self-constraining stress, the other is external constraining stress ${ }^{[6]}$. The influence of compensating shrinkage on the two constraint stresses is analyzed as follows:

(1) The effect of compensating shrinkage on selfconfining stress

The principle of self-confining stress and cracking of mass concrete structure is shown in Fig.1.

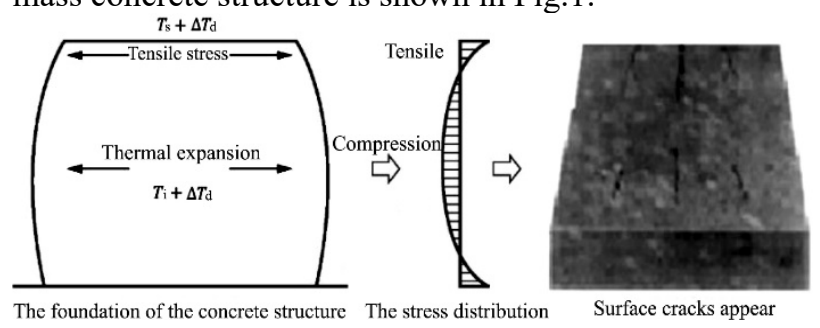

Fig. 1 Self-confining stress of mass concrete structure and its principle of cracking

The control condition of self-restrained cracking of mass concrete is that the difference between internal temperature (Ti) of concrete and surface temperature (Ts) of concrete is not more than $25^{\circ} \mathrm{C}$, that is:

$$
\Delta \mathrm{T}=\mathrm{Ti}-\mathrm{Ts}<25^{\circ} \mathrm{C}
$$

Assuming that the expansion strain generated by adding expansion agent in concrete is $\varepsilon_{\mathrm{p}}$, which is converted to an equivalent temperature difference of $\Delta T_{d}=\varepsilon_{p} / \alpha_{0} \quad\left(\alpha_{0}\right.$ is the linear expansion coefficient of concrete), then the internal surface temperature difference is:

$$
\left(\mathrm{Ti}+\Delta \mathrm{T}_{\mathrm{d}}\right)-\left(\mathrm{T} \mathrm{s}+\Delta \mathrm{T}_{\mathrm{d}}\right)=\mathrm{Ti}-\mathrm{Ts}=\Delta \mathrm{T}
$$

It can be seen from Equation (2) that the addition of expansion agent to the mass concrete has no influence on the magnitude of the inner surface temperature difference $(\Delta \mathrm{T})$ of the mass concrete structure, no matter whether it has expansion effect or not. Therefore, the addition of expansion agent has no effect on the control of selfrestrained cracking of the mass concrete.

(2) The effect of compensating shrinkage on external confinement stress

The principle of external constraint stress and cracking of mass concrete structure is shown in Fig. 2.

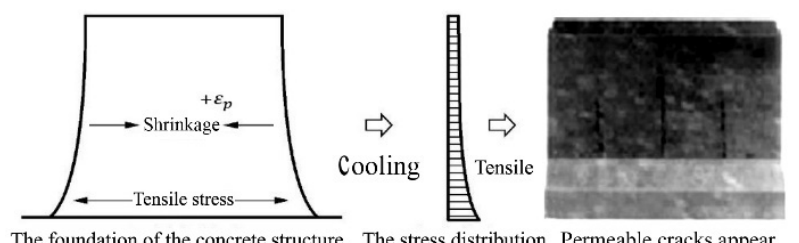

Fig. 2 External confinement stress of mass concrete structure and its principle of cracking
It can be seen from Fig. 2 that if the expansion agent added into the mass concrete produces the expansion strain $\varepsilon_{\mathrm{p}}$, it can play a part of compensating role in the external constraint cracking.

\subsection{Applicable conditions for shrinkage compensation and crack control of mass concrete}

It can be seen from the above analysis that the method of compensating the shrinkage of concrete to control the crack of mass concrete is only applicable to the condition of crack caused by external constraint stress, but has no effect on crack caused by self-constraint stress.

\section{Experimental study on shrinkage compensation of HCSA mass concrete}

\subsection{Background of experimental research}

The open section OW1-1 of the west artificial island of the Hong Kong-Zhuhai-Macao Bridge is $16.5 \mathrm{~m}$ long, with a maximum thickness of $3.15 \mathrm{~m}$ for the bottom plate, $1.10 \mathrm{~m}$ for the middle wall, $2.91 \mathrm{~m}$ for the side wall and $12 \mathrm{~m}$ for the height. In the height direction of the open section, the concrete is poured in two times, that is, the whole bottom plate is poured in the first time, and the middle wall and two side walls are poured in the second time, using C45 concrete. Due to various reasons OW1-1 floor construction completion after nearly nine months on side wall, the wall of casting construction, the concrete floor, including cooling contraction, all kinds of contraction is most complete, so the bottom will be on the side wall, the wall of concrete after contracting form strong external constraints, leading to side wall, concrete crack in the wall. In addition, the open section side wall adopts the construction technology of fair-faced concrete, which requires that no cracks need to be repaired. Therefore, it is very difficult to control the cracks in the open section side wall and middle wall. In order to control the crack in the side wall and middle wall, according to the research results in the literature ${ }^{[5]}$, it is proposed to add calcium sulfoaluminate-calcium oxide expansion agent (HCSA) into the concrete to compensate the shrinkage of the concrete in the side wall and middle wall, so as to avoid or reduce the crack. However, the HZMB is a major engineering project that attracts worldwide attention, and we must ensure that every technical measure is reliable and effective. Therefore, the expansion effect of HCSA in mass concrete must be confirmed by test before construction.

\subsection{Test concrete mix ratio}

C45 concrete was used in the test, and its mix ratio was listed in Table 1. The dosage of cementitious material was $420 \mathrm{~kg} / \mathrm{m} 3$, with the mix ratio of C-0 without expansion agent, and $6 \%$ of the dosage of cementitious material was replaced by HCSA expansion agent in the mix ratio of C1. 
Table $1 \mathrm{C} 45$ concrete mix ratio used in the test $\left(\mathrm{kg} / \mathrm{m}^{3}\right)$

\begin{tabular}{l|c|c|c|c|c|c|c|c}
\hline No. & Cement & Mineral powder & Fly ash & Expansive agents & Fine aggregate & Coarse aggregate & Water & Addition agent \\
\hline C-0 & 189 & 126 & 105 & 0 & 770 & 1064 & 143 & 3.36 \\
\hline C-1 & 189 & 126 & 80 & 25 & 770 & 1064 & 143 & 3.36 \\
\hline
\end{tabular}

\subsection{Laboratory test results}

The concrete shrinkage test specimen and the restricted expansion rate test specimen were made with the concrete mixture ratio numbered $\mathrm{C}-0$ and $\mathrm{C}-1$ respectively. The concrete shrinkage test specimen and the restricted expansion rate test specimen were tested in the laboratory respectively. The test results are shown in Figure 3.

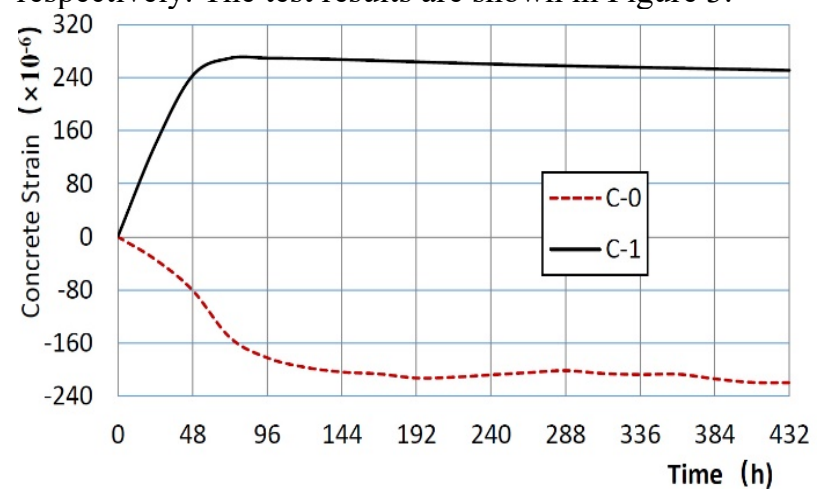

Fig. 3 Comparison of concrete shrinkage and limited expansion rate laboratory results

As can be seen from Fig. 3, when there is no expansion agent in the mix ratio, the concrete specimen has a shrinkage trend, and the maximum shrinkage strain is $219.6 \times 10^{-6}$ (negative value represents contraction). When HCSA expansion agent is mixed with $6 \%$ in the concrete mix, the expansion trend of the specimen range and the maximum limiting expansion rate is $269.4 \times 10^{-6}$ (positive value represents expansion).

\subsection{Field model test study}

\section{(1)Test method}

The test site was located at the seaside on the south side of the south mixing station on the west artificial island of the Hong Kong-Zhuhai-Macao Bridge, and the ambient temperature of the site was $26 \sim 35^{\circ} \mathrm{C}$. Two test blocks were cast on site, each of which was $8.2 \mathrm{~m}$ in length, $1.2 \mathrm{~m}$ in width and $1.6 \mathrm{~m}$ in height. The reinforcement and formwork of the test block were the same as the side wall of the open section, and the base was connected with the steel bar of the test block.

During casting, two bases with a thickness of $0.3 \mathrm{~m}$ and the same length and width as the test block shall be first poured. The test block 1 was poured with the mix ratio $\mathrm{C}$ 0 , and the test block 2 was poured with the mix ratio $\mathrm{C}-1$. 6 concrete strain gauges were arranged at different positions in the center and surface of the two test blocks, as shown in Fig. 4. In this strain test, Beijing Jikang BGK4200 vibrating string concrete strain gauge was adopted, and BGK-Micro-40 measuring unit was used to automatically collect temperature and strain data of a total of 12 strain gauges of two test blocks every $30 \mathrm{~min}$.

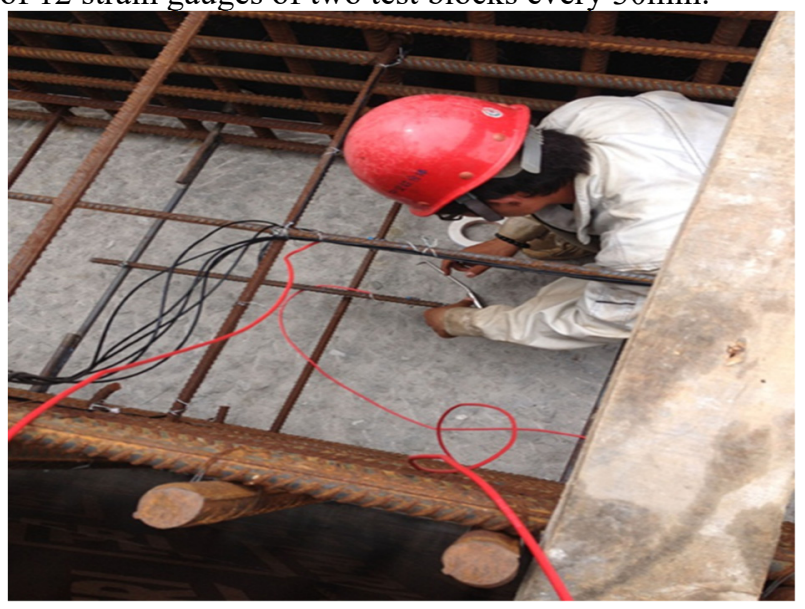

Fig. 4 Installation of test block concrete strain gauge

On April 18, 2015, the foundation casting of test block 1 and test block 2 was completed. On April 30, the upper concrete of test block 1 and test block 2 was poured at the same time. The pouring time interval of the upper and lower concrete was $12 \mathrm{~d}$, and the concrete pouring temperature was the same. Temperature and strain data are collected from the concrete covering strain timing.

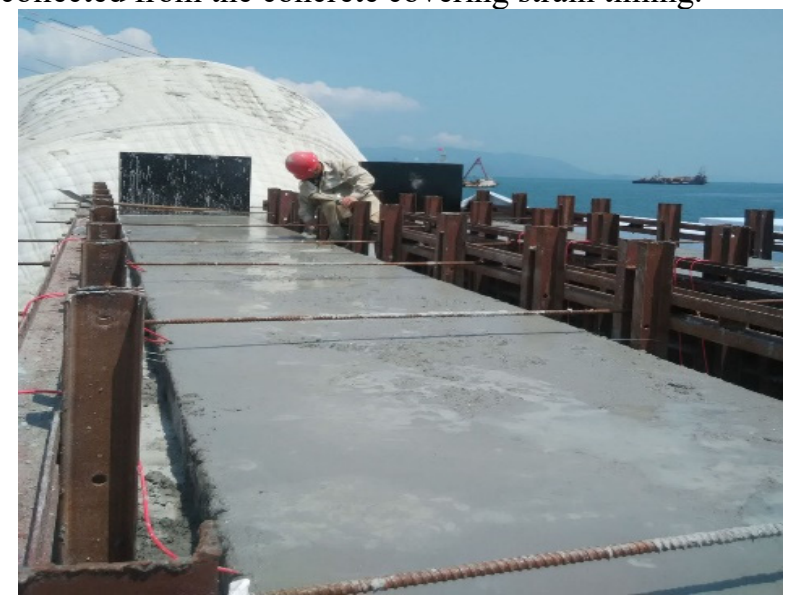

Fig. 5 Two mass concrete test blocks have been poured

(2) Analysis of concrete temperature test data

The temperature test data show that the temperature of the mass concrete test block with HCSA expansion agent is higher than that of the test block without HCSA expansion agent. Among them, the maximum temperature at the center point is about $3.9^{\circ} \mathrm{C}$ higher, and the arrival time of the temperature peak is about $5 \mathrm{~h}$ earlier, as shown in Fig. 6.

This indicates that the hydration reaction speed and hydration heat release of HCSA expansive agent are higher than that of cementitious materials used in concrete, which will lead to the increase of concrete's final cooling shrinkage, and also increase the risk of internal surface temperature difference exceeding the standard. 


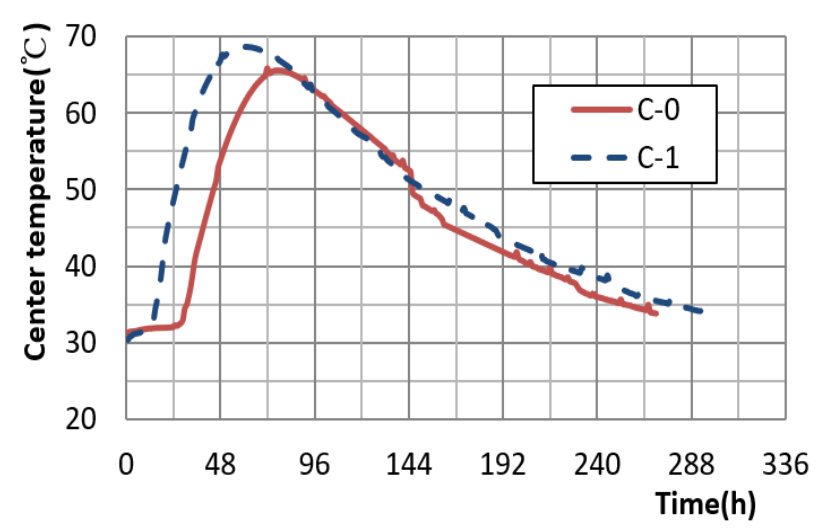

Fig. 6 Comparison of central temperature of concrete between two test blocks

(3) Test results and analysis of concrete strain test

The strain test results show that the concrete shrinkage strain values (excluding the influence of temperature change) of the test blocks with HCSA expansion agent are slightly greater than those of the concrete blocks without expansion agent.

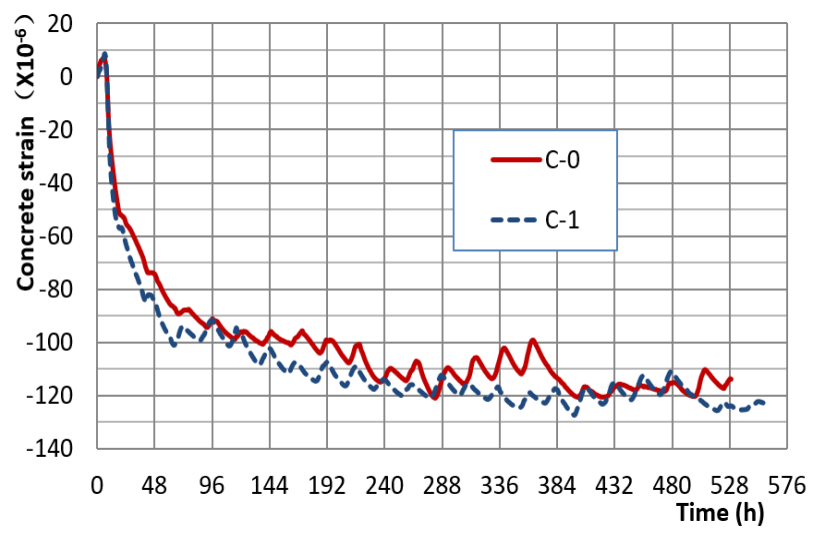

Fig. 7 Comparison of central strain of concrete between two test blocks

The strain test results show that the concrete shrinkage strain values (excluding the influence of temperature change) of the test blocks with HCSA expansion agent are slightly greater than those of the concrete blocks without expansion agent. The comparison of central strain of concrete between two test blocks is shown in Fig. 7, which indicates that HCSA expander cannot normally generate expansion in mass concrete, which is completely different from the results obtained in this laboratory and the research results in literature ${ }^{[5]}$. Compared with laboratory test conditions, the main difference of field model test is the difference of curing conditions and concrete temperature. Compared with laboratory test conditions, the main difference of field model test is the difference of curing conditions and concrete temperature. Compared with the experimental conditions of the research results in literature $^{[5]}$, the main difference of the field model test lies in the different ways of concrete temperature rise, which indicates that it is not reasonable to simulate the internal temperature change of mass concrete by changing the steam curing temperature.

According to the field model test results, HCSA expansion agent was not added to the concrete in the crack control process of the side wall and middle wall of the west artificial island of the Hong Kong-Zhuhai-Macao Bridge.

\section{Conclusion}

It can be seen from the above research that HCSA has a high hydration heat, and adding HCSA to mass concrete will increase the internal temperature rise of concrete and make the temperature peak arrive ahead of time, which is not conducive to crack control of mass concrete. HCSA can not play a normal expansion role in mass concrete, but will increase the shrinkage of concrete, and has a negative effect on crack control of mass concrete. It is unreasonable to study the expansion effect of HCSA expander in mass concrete by simulating the internal temperature change of mass concrete by changing the steam curing temperature. Therefore, HCSA expander cannot be used for crack control of mass concrete.

For the crack control of mass concrete, it is considered to develop an admixture which can slow down the hydration reaction rate of cementing material, so as to reduce the shrinkage of concrete and crack.

\section{References}

1. WANG T.M. (1997) Some basic physical and mechanical properties of concrete. In: Yue w. (Eds.), Control of Engineering Structures. China Architecture and Building Press, Beijing. pp. $24 \sim 25$

2. Wang X.G. (2017) Basic physical properties of concrete. In: Xia W. (Eds.), Practical Calculation Method of Temperature Stress of Mass Concrete and Example of Crack Control Engineering. People's Communications Press, Beijing. pp. 22

3. Yan P.Y., Lian H.Z. (2000) Several issues in the manufacture of shrinkage-compensating concrete using expansive agent. Journal of the Chinese ceramic society 2000,12:42 455

4. You B.K., Li G.M., (2001) Structural stability of mass shrinkage compensating concrete. Concrete,5:7 100

5. Tian Z.C., Li C.L. (2015) Influence of hydration environment and type of expansion agent on expansion performance of compensated shrinkage concrete. Expansive Agent \& Expansive concrete. 2015, 1:1 6

6. Wang X.G. (2017) Basic physical properties of concrete. 